\title{
Passivation of Recirculating Open Water Cooling Systems Using New Organic Passivator
}

\author{
Mahmoud Abbas, M. A. Shahin, ${ }^{*}$ Mohamed M. I. Ahmed, Magdy Kasem \\ Department of metallurgy and material engineering, Faculty of petroleum and mining engineering, Suez \\ University, Suez 43512, Egypt. \\ * Corresponding Author: Mohamed M. I. Ahmed (ma2080@pme.suezuni.edu.eg)
}

\begin{abstract}
It is well know that recirculating open cooling water system at metal/ water surface contact appear frequent corrosion products, like scales, foaling and material losses which are have great effect on cooling process.

Passivation helps to maintain clean heat transfer surface by inhibiting oxides scales through creating outer passive layer.

Passivators are substances which usually have a sufficiently high equilibrium potential and sufficiently low over potential decrease corrosion rate on attainment of passivity.

One of the most popular passivator is organic phosphate Phosphinosuccinic oligomer $\mathbf{C}_{\mathbf{1 5}} \mathbf{H}_{\mathbf{1 4}} \mathrm{O}_{\mathbf{4}} \mathbf{P}$ component (PSO)

The study of passivation of carbon steel pipe line in recirculating open cooling water system was the aim of this present work. Maximum efficiency of passivator was determined and surface morphology were investigated using optical, scanning microscopy, phase analysis of the formed protective layer was exam by XRD and EDX.

Corrosion in running water with and without PSO at $2 \mathrm{~m}^{3} / \mathrm{hr}$ flow rate was investigated using corrosion coupon rack.

It was found that $200 \mathrm{ppm}$ (PSO) decreases corrosion rate of carbon steel pipe in 3.5\% NaCL solution from 23 to 7 mpy in stagnate water corrosion testing, while in running water in $3.5 \% \mathrm{NaCL}$ solution it decreases from 45 to 18 mpy.

$\mathrm{XDR}$ showed that the protective layer due to passivation is mainly Magnetite $\left(\mathrm{Fe}_{3} \mathrm{O}_{4}\right)$ compound.
\end{abstract}

Key words: Corrosion, Low carbon steel, passivation, passive layer, organic passivator 


\section{Introduction}

Open recirculating cooling water systems or wet cooling towers are the most widely used designs in industry [1].

The open system uses the same water over and over again. Its most visible feature is the large, outdoor cooling tower that uses evaporation to release heat from the cooling water [2-3].

Due to the mechanism, this type of cooling tower is also called an evaporative cooling tower. This system consists of three main pieces of equipment: the recirculating water pump(s), the heat exchanger(s), and the cooling tower which are normally connecting with each other by AISI-1020 carbon steel pipe line [4].

Corrosion of open water cooling system causes two basic problems. The first and most obvious is the failure of equipment with the resultant cost of replacement and plant downtime. The second is decreased plant efficiency due to loss of heat transfer-the result of heat exchanger fouling caused by the accumulation of corrosion products [5].

One of corrosion prevention methods is passivation, "passivation" means to make something chemically passive, where passive is the opposite of active. Active surfaces react readily while passive surfaces are resistant to reactions, including corrosion reactions According to ASTM A 967 specification [6].

One of the biggest benefits to passive oxide layers is that when they arise naturally, they will also naturally "heal" if the surface of the metal is scratched or otherwise damaged, as the next layer of molecules will then bond with the environmental elements [7-8-9].

The effectiveness of passive oxide layers depends on the type of elements involved. Not all oxide layers are protective: If the oxide is porous enough for oxygen to get through, then no seal will be formed, and the metal beneath will continue to corrode [10-11-12].

Passivation process behavior of carbon steel in presence of Ethylenediaminetetraacetic acid (EDTA) was studies by P.S. Joshi they observed that protective magnetite thin film was formed on the steel surface [13].

The passive oxide film of carbon steel in saturated calcium hydroxide solution was investigated by P. Ghods, O.B. Isgor , J.R.Brown. They found that the thickness of the oxide films was approximately 4 $\mathrm{nm}[14]$.

Passivation of Carbon Steel by Sodium Borosilicate in Simulated Recirculating Cooling Water was clarified by Jun Cui, Wenjio, Donghai yuan[15].

Passivation of carbon steel in neutral aqueous solution by dicarboxylic acid was investigated by G. Chan- Rosado and M.A.Pech - Canul they discovered that the passive layer consisted of inner oxide region and outer hydroxylated region [16]. 
The present work was aimed at investigation the passivation of carbon steel by organic phosphate Phosphinosuccinic oligomer (PSO) in 3.5\% NaCL solution using electrochemical measurements as well as corrosion coupon rack testing (running flow)

Surface morphology will be investigated using optical, scanning microscopy and phase analysis of the formed protective layer will be examined by XRD and EDX.

\section{Experimental}

2.1 Materials and Procedure/Preparation a cold rolled - AISI-1020 low carbon steel has been used in this study. Table 1 and 2 summaries the chemical composition and mechanical proprieties of the steel under investigation.

Table (1): Chemical composition of AISI-1020

\begin{tabular}{|c|c|c|c|c|c|c|c|c|c|c|c|c|c|c|c|}
\hline C & Si & $\mathrm{mn}$ & $\boldsymbol{P}$ & $\mathrm{S}$ & $\mathrm{Cr}$ & $\mathrm{Ni}$ & $\mathrm{Cu}$ & $\mathrm{Mo}$ & $\mathrm{Alt}$ & $\mathrm{Ca}$ & $\boldsymbol{V}$ & $\mathrm{Nb}$ & $\mathrm{Ti}$ & $\mathrm{Sn}$ & $\mathbf{B}$ \\
\hline 0.29 & 0.266 & 1.198 & 0.01 & 0.024 & 0.06 & 0.061 & 0.206 & 0.005 & 0.001 & 0.0013 & 0.003 & 0.003 & 0.002 & 0.014 & 0.003 \\
\hline
\end{tabular}

Table (2): Mechanical proprieties

\begin{tabular}{|c|c|c|c|c|c|c|}
\hline Heat No & Bundle. No. & $\begin{array}{c}\text { Nominal } \\
\text { diameter. }\end{array}$ & $\begin{array}{c}\text { YS } \\
\text { (N/mm2) }\end{array}$ & $\begin{array}{c}\text { UTS } \\
\text { (N/mm2) }\end{array}$ & $\begin{array}{c}\text { EL\% } \\
\text { (5d) }\end{array}$ & (UTS/YS) \% \\
\hline $\mathbf{1 9 1 3 7 0 1}$ & $\mathbf{2 1 9 1 9 4 9 0 0}$ & 16.00 & 548 & 699 & 20 & 1.28 \\
\hline
\end{tabular}

Organic passivator was used in this study is phosphate Phosphinosuccinic oligomer (PSO) which have the following chemical formula and structure which have been tested in 3.5\% NaCL solution.

\section{Chemical formula and structure of Passivator.}

Passivator: Organic Phosphate Phosphinosuccinic oligomer (PSO)

Chemical formula: $\mathrm{C}_{15} \mathrm{H}_{14} \mathrm{O}_{4} \mathrm{P}$

\section{Structure:}

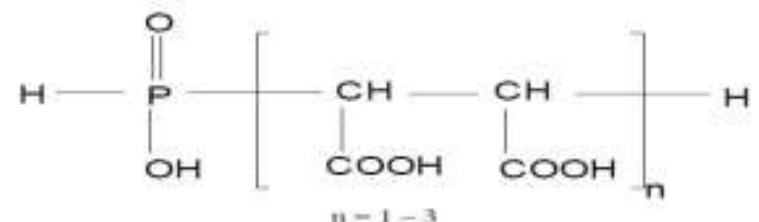




\subsection{Specimen Preparation and Characterization}

For testing and calculating the passivator efficiency and corrosion rate at different concentrations of passivator, specimens of $\left(20 \times 20 \times 1 \mathrm{~mm}^{3}\right)$ were utilized, which were abraded with different sizes of emery papers and polished with polishing clothes up to 1200 soaked in alumina solution was used to polishing then rinsed and air-dried. To ensure that the specimens were free of dust, oil, and extraneous materials, they were washed with ethanol in an ultrasonic bath and then cooled mounted. The test solutions were prepared by adding 50, 75, 100, 125, 150, 175, 200, 225 and $250 \mathrm{ppm}$ from PSO to a $3.5 \%$ NaCL solution. characterize the passivation film of the passivaded-steel, X-ray diffraction (XRD) patterns were recorded by a Siemens D5000 powder diffract meter equipped with $\mathrm{Cu}-\mathrm{Ka}$ radiation (Siemens D5000, Germany).Scanning electron microscopy compiled with an energy dispersive spectrometer (SEM-EDS, Jeol JSM-6360LA, Japan) was used to investigate the microstructure of the passivated steel. Salt spray tester was also used for five days.

\subsection{Corrosion Rate Measurement}

Potentiodynamic polarization technique was used to study the corrosion behavior of AISI 1020 carbon steel in 3.5\% NaCL solution with and without passivator. Potentiodynamic polarization experiments were carried out using Versastat3 (Potentiostat/Galvanostat Model, Germany). All potentials were measured concerning the SCE. All electrochemical experiments were conducted using a conventional three-electrode $250 \mathrm{ml}$ cell assembly, with the counter electrode made of platinum and saturated calomel electrode (SCE) as a reference electrode. A copper wire, $3 \mathrm{~mm}$ diameter, was mounted to the rear side of the samples as an electrical connection. The exposed surface of the specimen was flat with a cross-section area of $4 \mathrm{~cm}^{2}$.

The potentiodynamic current/potential curves were recorded by changing the electrode potential automatically from -2500 to $+2500 \mathrm{mV}$ with a scan rate of $1 \mathrm{mV} . \mathrm{S}-1$ and the corresponding current was recorded. The corrosion rate was calculated in Potentiodynamic polarization method from the following equation:

$$
\text { Corrosion rate }(\mathrm{CR})=\left(\mathbf{I}_{\text {corr }} \times \mathbf{E q} . \mathbf{W t} .\right) \backslash(\boldsymbol{\rho} \times \mathbf{F}) \ldots \ldots \ldots[1]
$$

where: $\mathrm{I}_{\text {corr }}$ is the corrosion current density, Eq. wt. is the equivalent weight of steel, $\mathrm{F}$ is the Faraday constant, and $\rho$ is the density of steel.

Running flow corrosion testing was carried out using corrosion coupon rack as described in ASTM D 2688-05 
Which is simulated to the conditions applied in industry used for calculation of erosion-corrosion. Specimens were tested for one day in running flow of 3.5\% NaCL (Pressure $=3$ bar, Flow rate $2 \mathrm{~m}^{3} / \mathrm{h}$, $\mathrm{RPM}=2000)$

A specimen is cleaned, weighed, attached to a rope and put in the pipe.

The specimen is left in the device for specific time, then we take it out from the device, clean it from corrosion products, and weighed it again. Corrosion rate have been calculated. Then the process repeats again for many specimens with different values of Passivator and calculate the corrosion rate for all specimens to determine the effect of Passivator. Corrosion rate was calculated in running flow method by the following equation:

$$
\text { Corrosion rate }(\mathrm{CR})=\mathbf{5 3 4} \mathbf{W} / \mathrm{DAT} \text {. }
$$

Where: $\mathrm{W}$ is weight loss of the specimen, $\mathrm{D}$ is density of metal, $\mathrm{A}$ is specimen area and $\mathrm{T}=$ time of corrosion. Corrosion coupons are pre-weighed and measured metal strips which are mounted in a special pipe system called a coupon rack.

\section{Results and discussion}

Figure 1 shows the polarization curves from AISI 1020 carbon steel in $3.5 \% \mathrm{NaCL}$ solution with different concentrations of organic phosphate Phosphinosuccinic oligomer (PSO) at $25^{\circ} \mathrm{C}$ with 6.5-7.5.

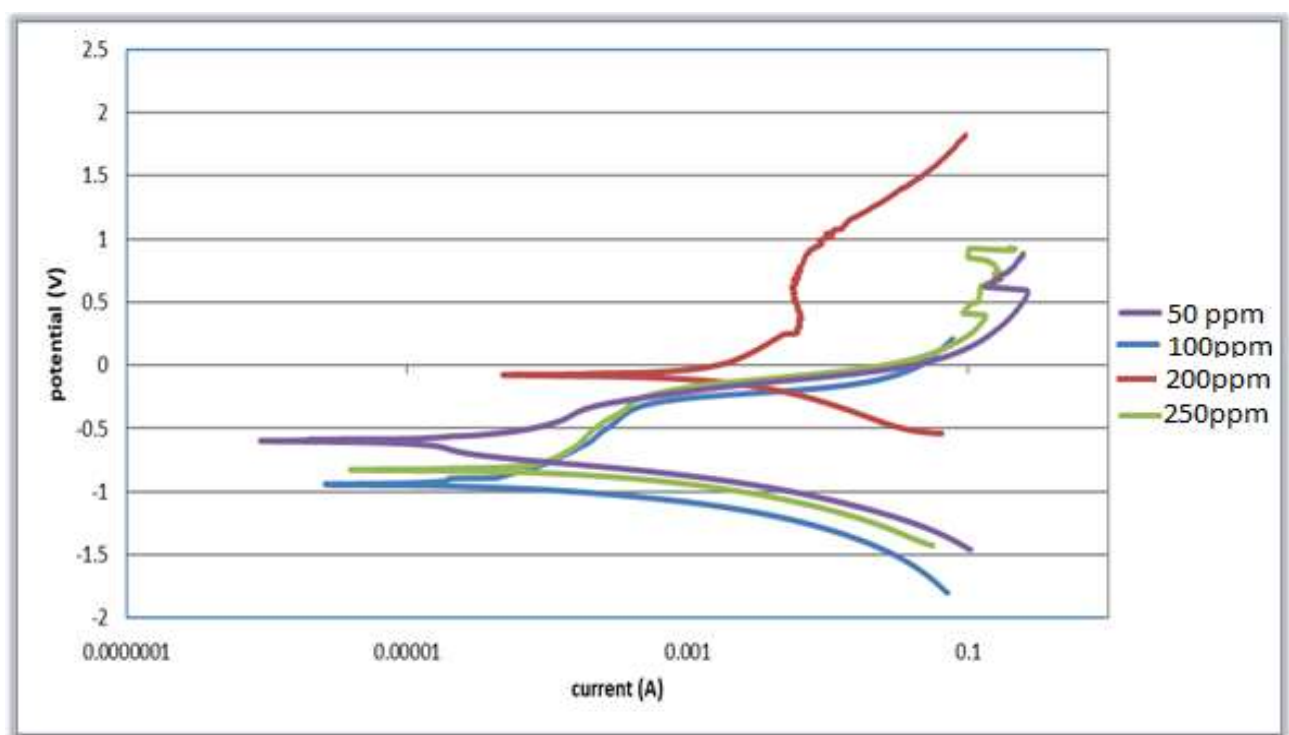

Figure 1 polarization curves for AISI 1020 carbon steel in $3.5 \% \mathrm{NaCL}$ solution at $25^{\circ} \mathrm{C}$ and $6.5-7.5 \mathrm{PH}$ with different concentration of organic phosphate Phosphinosuccinic oligomer (PSO). 
Figure 2 shows the effect of concentration of (PSO) on the corrosion rate of AISI 1020 carbon steel in 3.5\% $\mathrm{NaCL}$ solution at $25^{\circ} \mathrm{C}$ and 6.5-7.5 $\mathrm{PH}$ using potentiodynamic method. The addition of PSO leads to react with steel forming protective passive thin protective layer. This layer decrease the corrosion rate from 23 mpy to 7 mpy at $200 \mathrm{ppm}$.

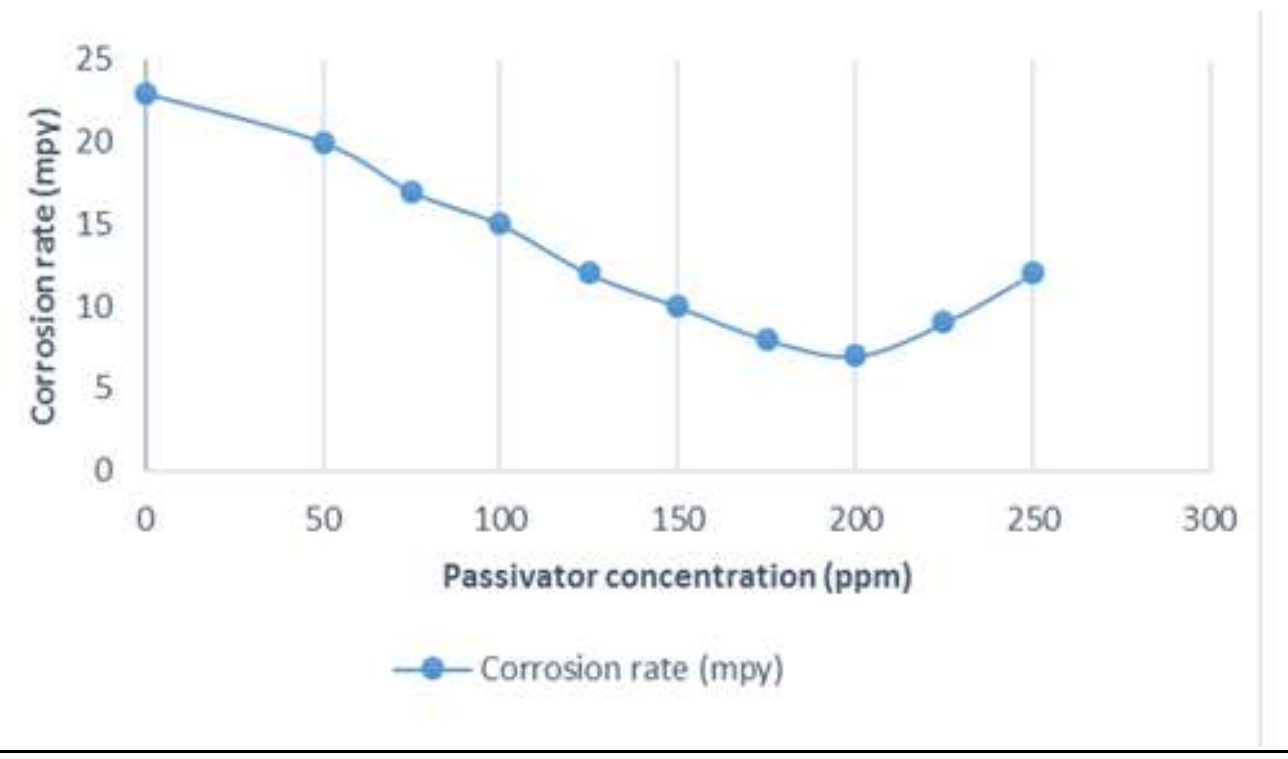

Figure 2 Effect of organic phosphate Phosphinosuccinic oligomer (PSO) concentration on the corrosion rate of AISI 1020 carbon steel in 3.5\% NaCL solution using potentiodynamic polarization technique at $25^{\circ} \mathrm{C}$ and 6.5-7.5 PH.

Figure 3 shows the effect of concentration of organic phosphate Phosphinosuccinic oligomer (PSO) on the corrosion rate of AISI 1020 carbon steel in $3.5 \% \mathrm{NaCL}$ solution at $25^{\circ} \mathrm{C}$ and $6.5-7.5 \mathrm{PH}$ using running flow method . The addition of PSO leads to react with steel forming protective passive thin layer from magnetite $\mathrm{Fe}_{3} \mathrm{O}_{4}$. This layer decrease the corrosion rate from 45 mpy to 18 mpy at $200 \mathrm{ppm}$.

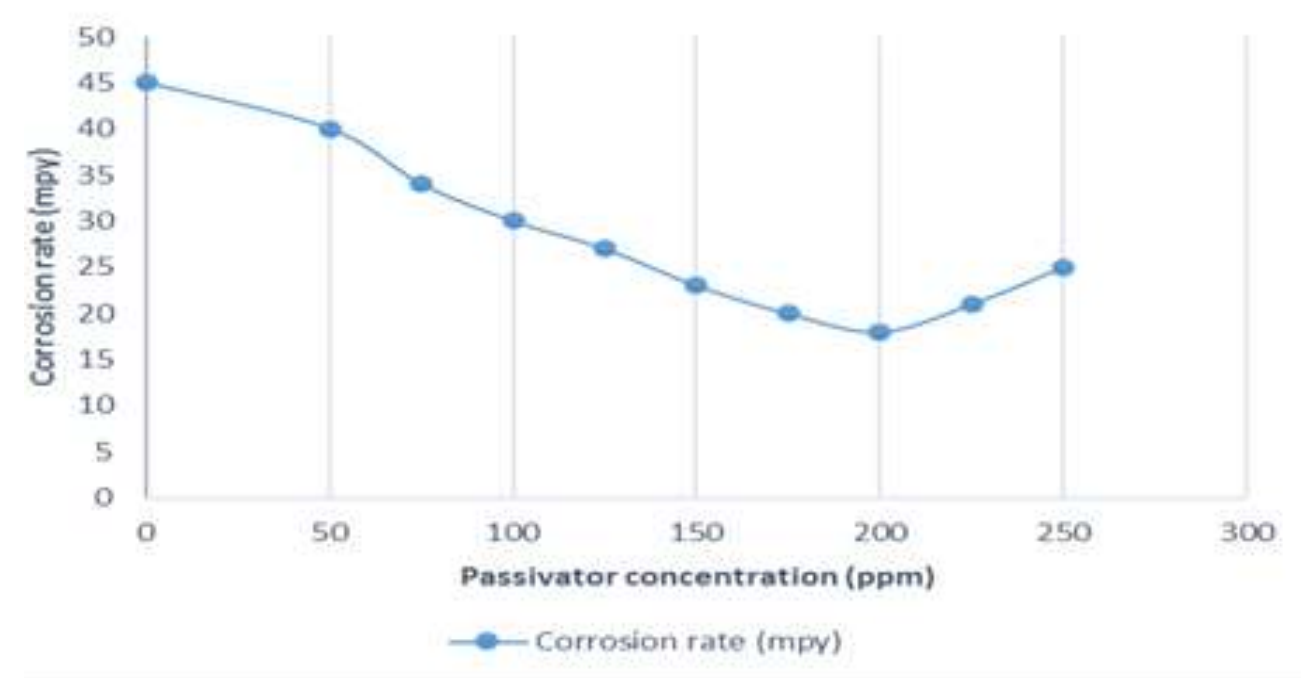


Figure 3 Effect of organic phosphate Phosphinosuccinic oligomer (PSO) concentration on the corrosion rate of AISI 1020 carbon steel in 3.5\% NaCL solution using potentiodynamic polarization technique at $25^{\circ} \mathrm{C}$ and $6.5-7.5 \mathrm{PH}$.

The corrosion rate (CR) is decreased with the addition of passivator. The corrosion rate is decreased to its lowest level when 200 ppm of PSO was used.

Table (3) shows corrosion rate and passivator efficiency using both potentiodynamic and running flow techniques on for AISI 1020 carbon steel in $3.5 \% \mathrm{NaCL}$ solution at $25^{\circ} \mathrm{C}$ and $6.5-7.5 \mathrm{PH}$ in present of studied passivator.

\begin{tabular}{|c|c|c|c|c|}
\hline $\begin{array}{c}\text { Passivator } \\
\text { Concentrations (ppm) }\end{array}$ & $\begin{array}{c}\text { Corrosion rates } \\
\text { Potentiodynamic (mpy) }\end{array}$ & $\begin{array}{c}\text { Passivator } \\
\text { efficiency \% }\end{array}$ & $\begin{array}{c}\text { Corrosion rates } \\
\text { Running flow (mpy) }\end{array}$ & $\begin{array}{c}\text { Passivator } \\
\text { efficiency } \%\end{array}$ \\
\hline 0 & 23 & - & 45 & - \\
\hline 50 & 20 & 13.1 & 37 & 17.8 \\
\hline 75 & 18 & 21.7 & 33 & 26.7 \\
\hline 100 & 15 & 34.8 & 25 & 37.8 \\
\hline 125 & 13 & 43.5 & 22 & 54.4 \\
\hline 150 & 9 & 52.2 & 18 & 60 \\
\hline 175 & 7 & 60.9 & 23 & 48.9 \\
\hline 200 & 10 & 69.6 & 29 & 35.6 \\
\hline 225 & 12 & 47.5 & & 25.5 \\
\hline 250 & & & 29 & \\
\hline
\end{tabular}

The results from running flow technique and potentiodynamic polarization technique show that the corrosion rate values using running flow technique is to be about twice the corrosion rate values using potentiodynamic polarization technique as showed in following figures 4 and 5 in present and absent of passivator. 


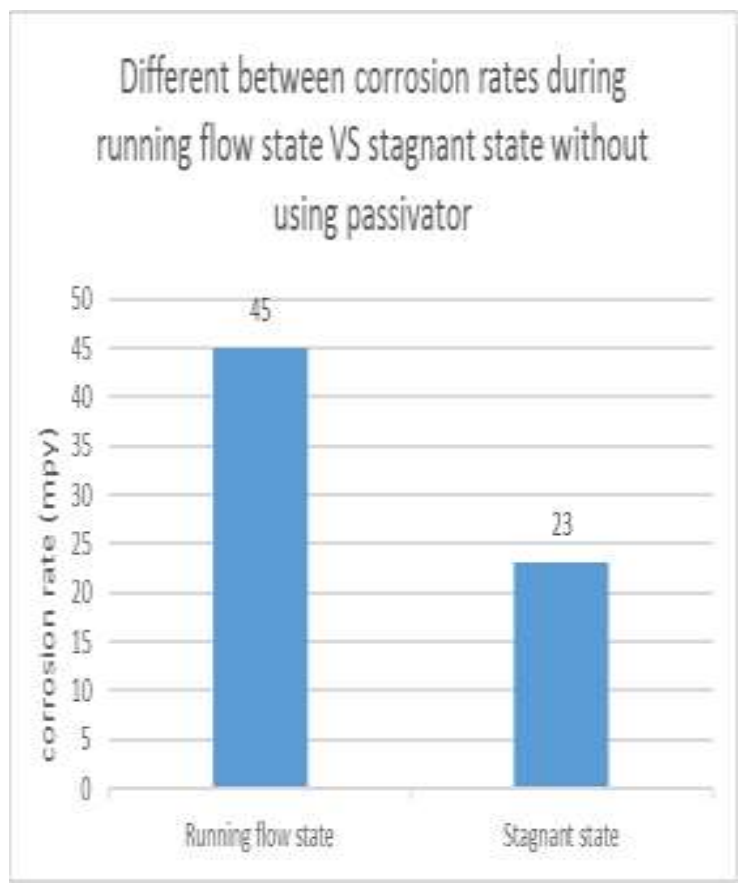

Figure 4 Corrosion rate for AISI-1020 carbon steel in 3.5\% NaCL solution in absent of passivator at $25{ }^{\circ} \mathrm{C}$ and $6.5-7.5 \mathrm{PH}$.

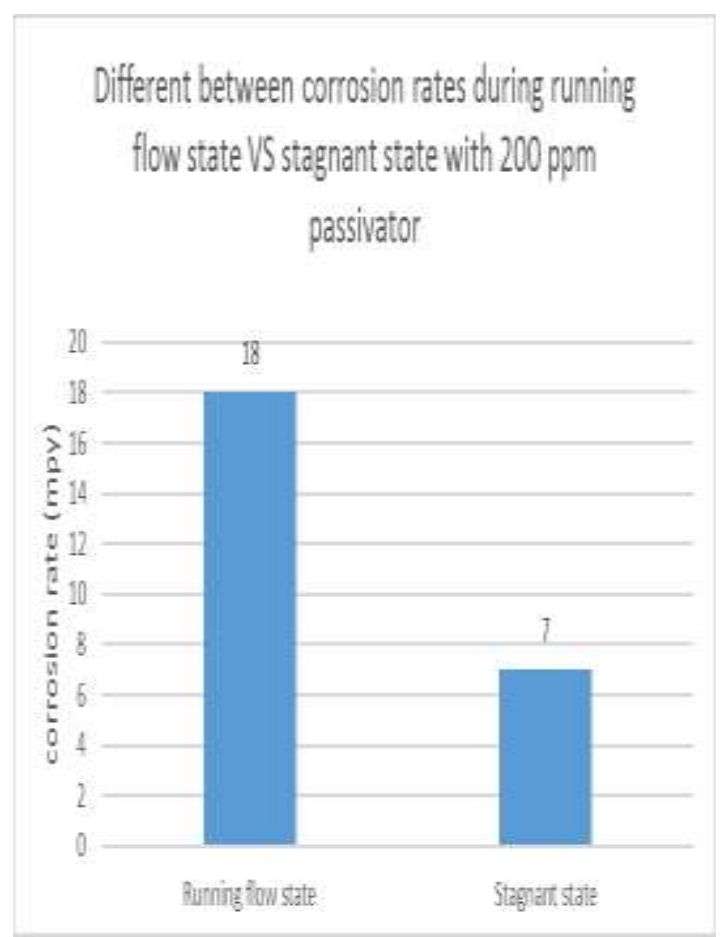

Figure 5 Corrosion rate for AISI-1020 carbon steel in 3.5\% NaCL solution in present of $200 \mathrm{ppm}$ passivator at $25{ }^{\circ} \mathrm{C}$ and $6.5-7.5$ $\mathrm{PH}$.

Figure 6 shows the XRD patterns for the AISI 1020 carbon steel specimen after immersion in 3.5\% $\mathrm{NaCL}$ solution with $200 \mathrm{ppm}$ (PSO) for 7 days. 


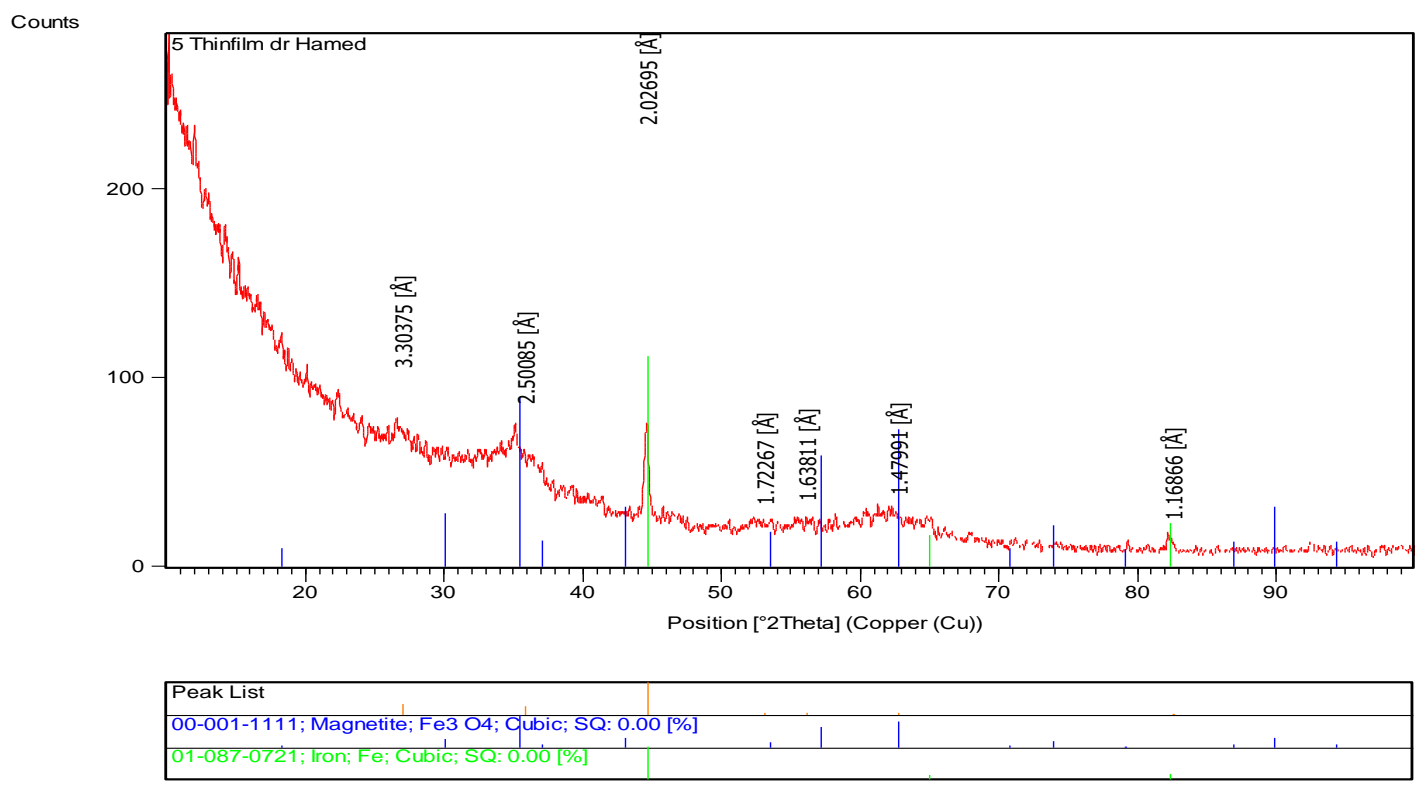

Figure 6 XRD patterns for AISI 1020 carbon steel specimen in the case of 200 ppm PSO passivator

It is clear that the passive layer was magnetite $\mathrm{Fe}_{3} \mathrm{O}_{4}$. The corrosion products caused by immersion in the test solution are represented by the compounds, as seen in figure 6. On the metal surface, a layer from iron oxide mainly magnetite is formed. The layer represent the protective film formed due to the interaction of iron with passivator molecules. As evidenced by the corresponding peaks, the intensity is much higher on the metal surface.

Additionally, the narrow peaks in the obtained XRD patterns suggested that the produced films were crystallized, resulting in a higher level of protection.

\section{Smart Quant Results}

\begin{tabular}{|cccc|} 
Element & Weight $\%$ & Atomic $\%$ & Error \% \\
\hline OK & 35.22 & 65.36 & 9.4 \\
\hline PK & 0.77 & 0.74 & 23.13 \\
\hline KK & 0.35 & 0.26 & 22.15 \\
\hline FeK & 62.7 & 33.34 & 2.8 \\
\hline MoL & 0.96 & 0.3 & 16.27 \\
\hline
\end{tabular}

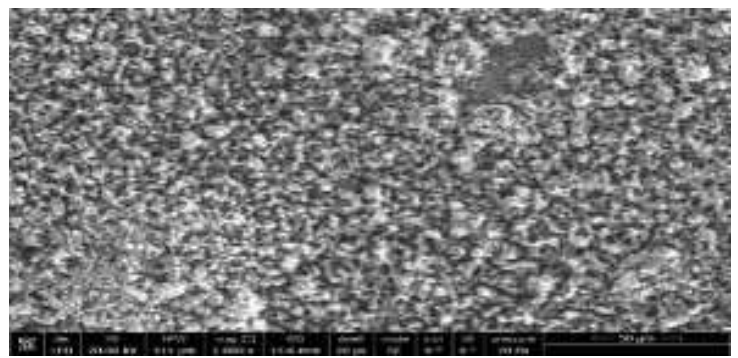

Figure 7 SEM image of passivation layer created for AISI 1020 carbon steel specimen in the case of 200 ppm PSO passivator 


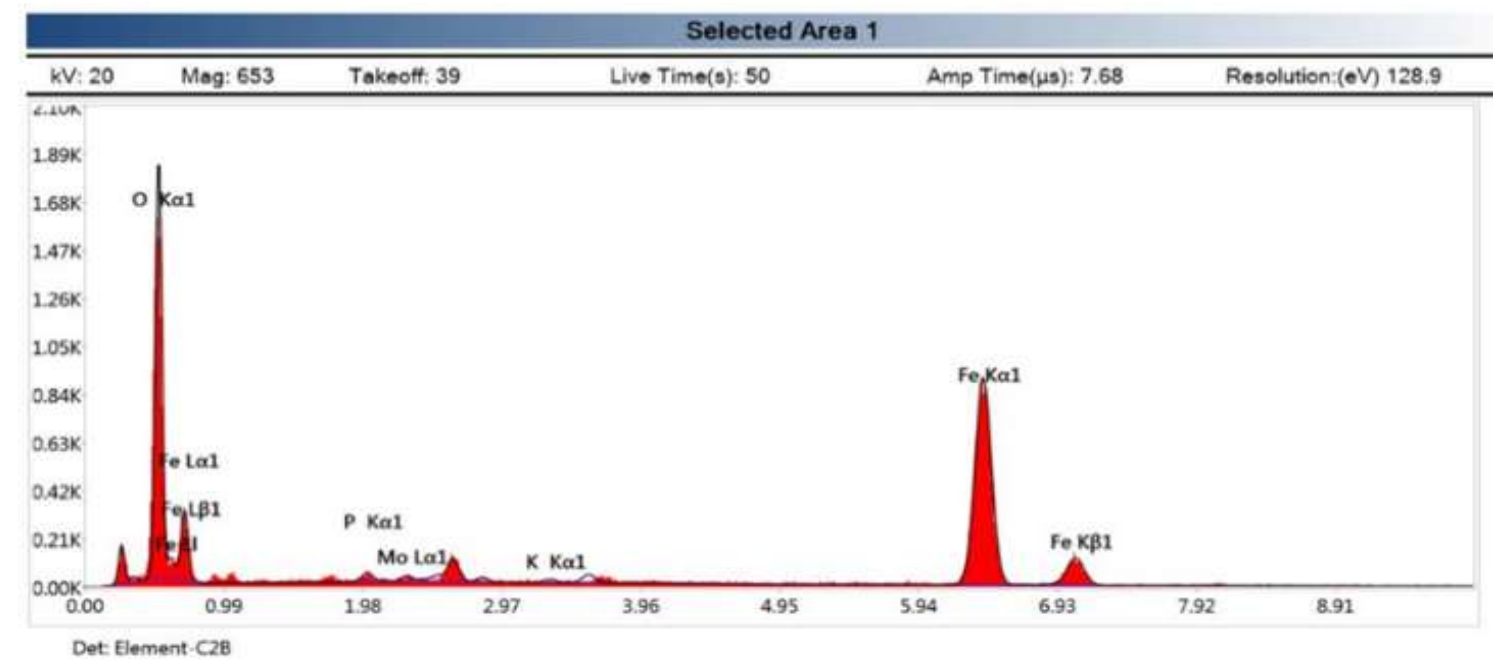

Figure 8 EDX for AISI 1020 carbon steel specimen in the case of 200 ppm PSO passivator for 15 days

By using optical microscope, protective iron oxide thin layer was showed as in figure 9 .

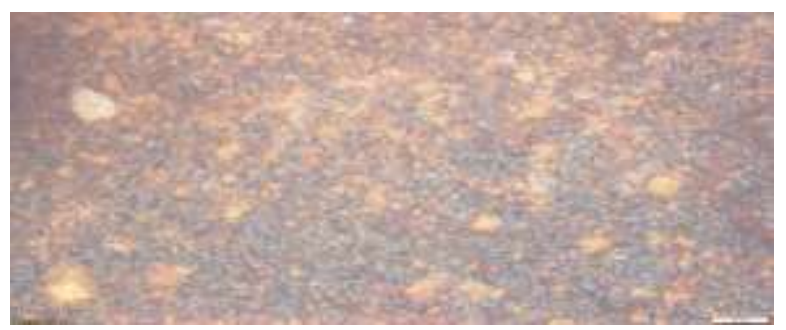

Figure 9 optical microscope image for created passive layer at AISI-1020 carbon steel in 3.5\% NaCL solution in present of 200 ppm passivator.

Salt spray test was carried out by (Alpha + ) Salt spray testing equipment with the following test conditions time $=5$ days, chamber temperature $=35^{\circ} \mathrm{C}, \mathrm{PH}=6.5$ to 7.2 and $5 \%$ sodium chloride aqueous solution.one day in mentioned equipment simulate one year in normal condition and it is shows high performance for created passive layer for the sample.

(a)

(b)

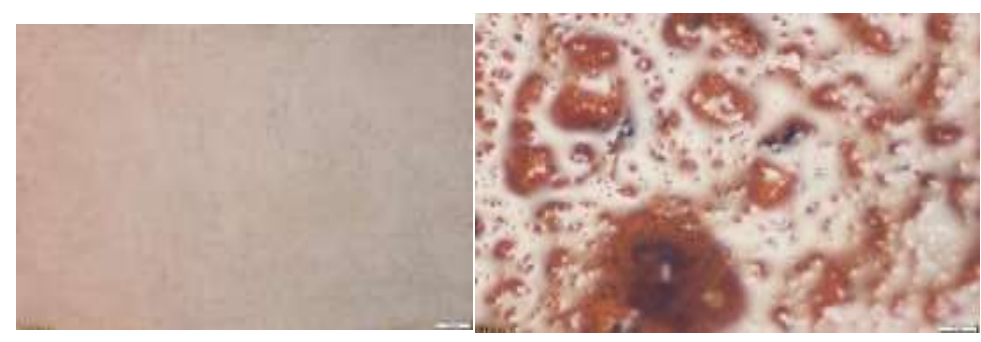

Figure (9) shows macrograph of steel samples after salt spray test lasted for 5 days (a) before salt spray (b) 200ppm passivator 


\section{Conclusion}

- The results from running flow test and potentiodynamic polarization technique show that 200 ppm passivator is the best value for protection the water-cooling piping system.

- In potentiodynamic polarization technique (stagnant), the corrosion rate of carbon steel decreases from about 23 mpy to about 7 mpy after adding 200 ppm passivator in $3.5 \% \mathrm{NaCL}$ solution.

- In running flow test, the corrosion rate of carbon steel decreases from about 45 mpy to about 18 mpy after adding 200 ppm passivator in 3.5\% NaCL solution.

- The results from running flow test and potentiodynamic polarization technique show that the corrosion rate values using running flow test is to be about twice the corrosion rate values using potentiodynamic polarization technique.

- Results of XRD, showed that Magnetite $\left(\mathrm{Fe}_{3} \mathrm{O}_{4}\right)$, which is the protective layer, is formed on the surface.

\section{Acknowledge}

We would like to express our special thanks of gratitude to Nalco. Company for their support by providing us by used passivator. 


\section{References}

1. Rutger Botermans, Peter Smith, "Advanced Piping Design", Science Direct, (2008).

2. A. Kayode Coker, "Ludwig's Applied Process Design for Chemical and Petrochemical Plants" (Fourth Edition), Volume 2, (2010).

3. Swapan Basu, Ajay Kumar Debnath, "Power Plant Instrumentation and Control Handbook" (Second Edition), (2019).

4. Suez, Water Technologies and solution, "handbook of Industrial Water Treatment", Chapter 31 Open Recirculating Cooling Systems , (2019).

5. S. N. Kazi, " Fouling and Fouling Mitigation on Heat Exchanger Surfaces", (2012).

6. ASTM A967,"Standard Specification for Chemical Passivation Treatments for Stainless Steel Parts",Volume:01.03, DOI:10.1520/A0967-05, (2018).

7. Fan Zhang, Pengfei Ju, Mengqiu Pan, "Slef-healing Mechanisms in Smart Protective Coatings", (2018).

8. Wojciech Kiicinski, Stawomir Dyjak. "Transition metal impurities in carbon-based materials: Pitfalls, artifacts and deleterious effects", Carbon, Volume 168, Pages 748-845. (2020).

9. A. Balamurugan, S.Rajeswani, G. Balossier,"Corrosion aspects of metallic implants - An Overview" Materials and Corrosion, 59,No.11DOI: 10.1002/maco.200804173 , (2008),

10. B. Elsener, A. Rossi, "Passivation of steel and stainless steel in Alkaline Media Simulating Concret", Encyclopedia of Interfacial Chemistry, 2018).

11. John Campbell, "The Fracture of Liquids", The Mechanisms Of Metallurgical Failure,(2020).

12. A.S. Khanna, "High Temperature Oxidation" Handbook of Environmental Degradation of Materials, (Second Edition), (2012).

13. P.S. Joshi, G. Venkateswaran, K.S. Venkateswru "Passivation Behavior Of Carbon Steel Alloy In The Presence Of EDTA, Ni(II) EDTA, and LiOH at 473 K" Corrosion 48 (06) , (1992).

14. P. Ghods, O.B. Isgor, J.R.Brown "XPS depth profiling study on the passive oxide film of carbon steel in saturated calcium hydroxide solution and the effect of chloride on the film properties", Applied Surface Science, Volume 257, Pages 4669-4677, (2011).

15. Jun Cui, Wenjio, Donghai yuan," Effect of pH on the Passivation of Carbon Steel by Sodium Borosilicate Controlled-Release Inhibitor in Simulated Recirculating Cooling Water", Industrial \& Engineering Chemistry Research 56(25), DOI:10.1021/acs.iecr.7b01433, (2017).

16. G. Chan- Rosado and M.A.Pech - Canul " Influence of native oxide film age on the passivation of carbon steel in neutral aqueous solutions with a dicarboxylic acid", Corrosion Science Volume 153, Pages 19-31, (2019). 